\title{
A presença de oscilações no enquadramento midiático e de interpretações fragmentadas na cobertura do consumo de crack
}

\author{
The presence of oscillations in the media framework and fragmented \\ interpretations in the coverage of the crack consumption
}

\section{La presencia de oscilaciones en los marcos mediáticosy de interpretaciones fragmentadas en la cobertura del uso de crack}

Fernanda Vasques Ferreira ${ }^{1, a}$

fernanda.jornalista82@gmail.com | http://orcid.org/000o-0003-4242-0057

Dione Oliveira Moura ${ }^{2, b}$

dioneoliveiramoura@gmail.com | http://orcid.org/0000-0003-2857-3284

\footnotetext{
${ }^{1}$ Universidade Federal do Oeste da Bahia, Centro Multidisciplinar de Santa Maria da Vitória, Curso de Publicidade e Propaganda. Santa Maria da Vitória, BA, Brasil.

2 Universidade de Brasília, Faculdade de Comunicação, Curso de Graduação e Pós-Graduação. Brasília, DF, Brasil.

a Doutorado em Comunicação pela Universidade de Brasília.

' Doutorado em Ciências da Informação pela Universidade de Brasília.
}

\section{Resumo}

O estudo que fundamenta este artigo parte das premissas de que o Jornal Nacional da Rede Globo é um jornal de referência e de grande audiência, e de que a imprensa, ao enfocar determinado assunto, e apresentar um enquadramento específico para tal tema - no caso, o consumo do crack e as consequências sociais desse consumo - influencia, de certa forma, a percepção pública sobre o tema. Quais são os enquadramentos midiáticos dados ao consumo do crack e às implicações sociais da droga na cobertura televisiva feita pelo Jornal Nacional, da Rede Globo? O objetivo é compreender os enquadramentos fornecidos pelo telejornal acerca do consumo do crack, a partir da análise sobre o modo como esse noticiário organiza o conteúdo informativo. Foi aplicada a análise de conteúdo nas reportagens veiculadas no JN no período de 2012 a 2017 e nas entrevistas realizadas com os repórteres responsáveis pela cobertura. Identificamos que o telejornal enquadrou o consumo do crack e as implicações sociais decorrentes do uso da droga como um problema de saúde pública e como um problema social crônico (em menor medida), por um lado; e, por outro, como um problema de segurança pública, em maior medida. A maneira como esse telejornal organiza e dá sentido à questão pode, potencialmente, influir na formulação de políticas públicas, assim como na maneira como a sociedade interpreta o assunto e dá significado ao quadro social do fenômeno do consumo do crack.

Palavras-chave: Enquadramento midiático; Consumo do crack; Interpretações fragmentadas; Telejornalismo; Jornal Nacional. 


\section{Abstract}

The study presented in this article is based on the assumptions that the Jornal Nacional (National News), broadcast by Rede Globo (Globe television networking), is a reference and large audience newscast and that the press, in focusing on a certain subject and presenting a specific framework for some theme - in this case, crack use and the social consequences of this use - influences, to some extent, the public perception of the topic. What are the frameworks given by media coverage to crack use and the social implications of the drug on televisionthrough the newscast called Jornal Nacional, broadcast by Rede Globo? The goal is to understand the frameworks provided by this newscast about crack consumption, based on the analysis of how it organizes informative content. The content analysis was applied to the reports exhibited in JN from 2012 to 2017 and to interviews with reporters responsible for the coverage of the crack. We identified that the newscast framed the crack use and the social implications of the drug use as a public health problem and as a chronic (to a lesser extent) social problem, on the one hand; and as a public safety issue to a greater extent on the other hand. The way of this newscast organizing and to give meaning to the issue can potentially influence the formulation of public policies, as well as the way of society interpreting the issue and to give meaning to the social context of the crack consumption phenomenon.

Keywords: Media framework; Crack consumption; Fragmented interpretations; Telejournalism; Jornal Nacional.

\section{Resumen}

El estudio que fundamenta este artículo parte de los supuestos de que el Jornal Nacional de la Rede Globo es un noticiero de referencia y de mucha audiencia, y que la prensa, al centrarse en un tema en particular y presentar un marco específico para ese tema - en este caso, el uso del crack y las consecuencias sociales del uso del crack - influye, en cierta medida, en la percepción pública del problema. ¿Cuáles son los marcos mediáticos dados al uso de crack y a las implicaciones sociales de la droga en la cobertura televisiva de Jornal Nacional de la Rede Globo? El objetivo es comprender los marcos proporcionados por las noticias del telediario acerca del consumo de crack, basada en el análisis de como ese noticiero organiza el contenido informativo. El análisis de contenidos se aplicó a los reportajes difundidas en el JN de 2012 hasta 2017 y a las entrevistas con los reporteros responsables de la cobertura del crack. Identificamos que el noticiero enmarcó el uso del crack y las implicaciones sociales del uso suyo como un problema de salud pública y como un problema social crónico (en menor medida), por un lado; y como un problema de seguridad pública en mayor medida, por otro lado. La manera como ese telediario organiza y da sentido al problema pueden potencialmente influir en la formulación de políticas públicas, así como en la forma de la sociedad interpretar el tema y de dar sentido al contexto social del fenómeno del consumo de crack.

Palabras clave: Marcos mediáticos; Consumo del crack; Interpretaciones fragmentadas; Periodismo televisivo; Jornal Nacional.

Contribuição dos autores:

Concepção e desenho do estudo: Fernanda Vasques Ferreira e Dione Moura. Aquisição, análise ou interpretação dos dados: Fernanda Vasques Ferreira.

Redação do manuscrito: Fernanda Vasques Ferreira e Dione Moura.

Revisão crítica do conteúdo intelectual: Fernanda Vasques Ferreira e Dione Moura.

Declaração de conflito de interesses: não há.

Fontes de financiamento: Conselho Nacional de Desenvolvimento Científico e Tecnológico.

Considerações éticas: não há.

Agradecimentos/Contribuições adicionais: As autoras agradecem aos 11 repórteres do Jornal Nacional que concederam entrevista e também agradecem ao neurocientista Carl Hart.

Histórico do artigo: submetido: 25 ago. 2019 | aceito: 07 fev. 2020 | publicado: 30 jun. 2020.

Apresentação anterior: não houve.

Licença CC BY-NC atribuição não comercial. Com essa licença é permitido acessar, baixar (download), copiar, imprimir, compartilhar, reutilizar e distribuir os artigos, desde que para uso não comercial e com a citação da fonte, conferindo os devidos créditos de autoria e menção à Reciis. Nesses casos, nenhuma permissão é necessária por parte dos autores ou dos editores. 


\section{Introdução}

Segundo a Confederação Nacional dos Municípios ${ }^{1}$, o consumo do crack está presente em nove de cada dez municípios brasileiros e consiste em uma epidemia. Dados do III Levantamento Nacional de Álcool e Drogas, realizado em 2017 e divulgado em 2019 sob a coordenação da Fundação Oswaldo Cruz², indicam que a droga ilícita mais consumida no Brasil é a maconha e que aproximadamente 1,4 milhão de pessoas entre 12 e 65 anos relataram - nas entrevistas realizadas - ter feito uso de crack e similares alguma vez na vida, o que corresponde a 0,9\% da população de pesquisa. Desse total, 1,4\% é constituído por homens e $0,4 \%$ por mulheres. Os números do levantamento apresentam uma discrepância em relação à Pesquisa Nacional do Uso de Crack, realizada pela mesma instituição em 2013. A pesquisa realizada ${ }^{3}$ apresentou dados superiores ao levantamento de 2019, uma vez que, nesse ano, o levantamento feito foi domiciliar. Esse dado é importante de ser considerado, já que os usuários de crack compõem população majoritariamente marginalizada, em situação de rua. A pesquisa denuncia que o consumo da droga é um fenômeno do espaço público e tem pouca visibilidade dentro dos lares brasileiros. A investigação esclarece também que a droga mais consumida no país não é o crack, mesmo que, por vezes, os noticiários brasileiros divulguem uma 'epidemia do crack' no Brasil.

A formulação de Lippmann - "O mundo que temos que considerar está politicamente fora de nosso alcance, fora de nossa visão e compreensão"4 (p. 40) - é atual e realça a importância dos meios de comunicação na contemporaneidade. Assim, grande parte de nosso quadro de referencialidades é fornecido pela mídia.

Ademais, no cenário de consumo midiático brasileiro, o Jornal Nacional da Rede Globo continua a ser uma referência em termos de construção da agenda pública, até o momento de realização da presente pesquisa, mesmo com a emergência das redes sociais. O conceito de enquadramento formulado por Goffman ${ }^{5}$ vem somar ao nosso estudo, e assim alicerçamos nossas duas premissas: de que o JN, mesmo com a emergência das redes sociais, continua, até o momento do estudo, a ser uma referência em termos de pautar a agenda pública; e, ainda, de que a imprensa, ao enfocar determinado assunto, e apresentar um enquadramento específico para tal tema - no caso o consumo do crack e as consequências sociais desse consumo - influencia, de certa forma, a percepção pública sobre o tema.

Esse contexto dos meios de comunicação e da comunicação como uma das fontes de orientação para os assuntos públicos, foi que nos fez realizar essa pesquisa com o objetivo de investigar a cobertura jornalística do Jornal Nacional, da Rede Globo sobre o consumo do crack e as implicações sociais decorrentes do uso da droga, de modo a compreender a possível relação existente entre a maneira como o tema é noticiado e apresentado pelo telejornal de forma a construir quadros de referencialidades e formas de compreender o assunto.

Para a realização de nosso estudo, o qual resultou na tese de doutoramento da autora principal ${ }^{6}$ deste artigo, sob orientação da coautora, Dione Oliveira Moura, selecionamos as reportagens sobre consumo do crack veiculadas no período de 2012 a 2017 no Jornal Nacional. O nosso corpus de análise se constitui de 19 reportagens cujos repórteres responsáveis pela produção foram entrevistados em nossa pesquisa, uma vez que compreendemos que o modus operandi e a lógica operativa da produção noticiosa devem ser levados em conta. Como método de análise, valemo-nos das contribuições da análise de conteúdo, de Bardin7, e das referências teóricas de Goffmann ${ }^{5,8}$, Porto $^{9} \mathrm{e} \mathrm{Sena}^{10}$. 


\section{A construção de perspectivas a partir do enquadramento midiático}

O conceito de enquadramento, com base na noção de orientação da estrutura, constitui importante instrumento teórico-metodológico para este artigo no sentido de oferecer os tipos de enquadramentos produzidos e veiculados pelo Jornal Nacional no que se refere às notícias sobre o crack. Porto9 explica que, quando se discute o papel da mídia na política, frequentemente, a mídia é entendida como fonte de informação, e seu papel é tido como o de informar os cidadãos. A despeito de a comunicação midiática ter papel preponderante na sociedade no sentido de estabelecer um espaço público, o mito da objetividade e da imparcialidade já não corresponde mais a um paradigma possível, tendo em vista suas limitações. Por isso, uma das alternativas tem sido o conceito de enquadramento (framing). Porto ${ }^{9}$, ao citar Robert Hackett (1993), considera fundamental seu argumento de que os conceitos de parcialidade e objetividade constituem um suporte teórico frágil e que já não é mais suficiente pressupor que a comunicação seja imparcial, como se os conteúdos pudessem ser objetivos e desvinculados da realidade que os cerca. Segundo Hackett apud Porto ${ }^{9}$, embora esses conceitos tenham valor normativo e empírico, é necessário avançar com as pesquisas sobre o papel da mídia. Sobre isso, o autor sugere a substituição do conceito de parcialidade pelo de orientação estruturada.

Para $\mathrm{McCombs}^{11}$, às vezes, o conceito de enquadramento se refere a uma delimitação determinada no conteúdo midiático e, outras vezes, ao processo de enquadramento, à origem dos enquadramentos ou à sua difusão pelos meios de comunicação: "Aplicado à agenda midiática, um enquadramento é a ideia central organizadora do conteúdo informativo que confere um contexto e sugere qual é o tema mediante o uso da seleção, da

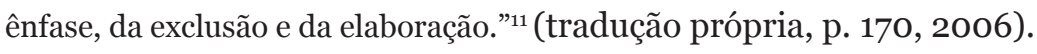

A obra Frame analysis, do sociólogo Erving Goffman ${ }^{8}$, é tida como referência no uso sistemático do conceito de enquadramento. Para Porto 9 “[...] Goffman define enquadramentos como os princípios de organização que governam os eventos sociais e nosso envolvimento nestes eventos. Segundo o autor, tendemos a perceber os eventos e situações de acordo com enquadramentos que nos permitem responder à pergunta: "O que está ocorrendo aqui?". Neste enfoque, enquadramentos são entendidos como marcos interpretativos mais gerais construídos socialmente que permitem as pessoas fazer sentido dos eventos e das situações sociais” " (p. 4).

Goffman ${ }^{5}$ acredita que, na sociedade ocidental, os indivíduos tendem a reconhecer os acontecimentos e incluí-los num quadro esquemático de interpretação. Esse quadro é designado como primário, uma vez que é convertido em algo significativo, o que de outro modo seria um aspecto da cena sem significação. Os esquemas primários, segundo Goffman ${ }^{5}$, variam de acordo com o grau da organização ou com a estrutura social: "Contudo, seja qual for o grau de organização, cada esquema primário permite a seu usuário localizar, perceber, identificar e etiquetar um número aparente de ocorrências concretas, definidas em seus termos”5 (p. 45).

Os definidores primários, segundo o autor, podem ser divididos em duas grandes classes de esquemas: os naturais e os sociais. Os primeiros dizem respeito a um dado inegável e inconteste relacionado com a natureza, com a ordem natural das coisas. São ocorrências consideradas não dirigidas, não orientadas e, portanto, desprovidas de quaisquer interferências humanas. Por outro lado, Goffman esclarece que os esquemas sociais "fornecem uma compreensão de fundo para os acontecimentos que incorporam a vontade, o objetivo e o esforço de controle de uma inteligência, de um agente vivo, sendo o principal deles o ser humano"5 (p. 46). $\mathrm{O}$ autor exemplifica que "Quando o sol se levanta, temos um acontecimento natural; quando se desce a persiana para impedir a entrada da luz, temos uma ação guiada”' (p. 49).

O conceito de enquadramento, então, pode ser compreendido como uma generalização que nos permite classificar e categorizar. "A noção cognitiva de frame (quadro) é como um conjunto de pressuposições e critérios avaliativos, dentro dos quais a avaliação pela pessoa de um determinado assunto se processa”"12 (p. 90).

Os enquadramentos noticiosos chamam a atenção para determinados pontos e excluem outros. Iluminar alguns atributos e obscurecer outros configura uma percepção do acontecimento, ampliando a visibilidade 
de uns elementos em detrimento de outros, sugerindo explicações causais e avaliações normativas sobre o fato noticiado. Os enquadramentos vão além: destacam os dados fornecidos por determinada fonte em detrimento de outra, evidenciam as ações de determinados agentes, minimizando outros, tornando-os, por vezes, sem relevância. De acordo com Correia ${ }^{12}$, a inclusão ou a exclusão de determinados detalhes dos acontecimentos e a atribuição de relevância ou não de determinado fato dependem da classificação ou categorização que recebem. Trata-se do que Porto ${ }^{9}$ definiu como padrões de apresentação, seleção e ênfase utilizados no jornalismo.

Assim como há formas de enquadrar, há problemas de enquadramento ou o que Goffman define como enquadramento errôneo: "Em nossa sociedade muitas vezes confiamos aos especialistas a tarefa de esclarecer a ambiguidade do quadro"5(p. 372). O autor exemplifica com o caso da morte de um homem, fruto de uma briga de bar em que, para compreender, chamamos um médico legista para determinar a causa da morte: se uma causa natural e, portanto, um definidor primário natural - aneurisma -, ou se foi vítima de um golpe, o que situa o caso num quadro social, envolvendo um agente externo. "A análise de quadros recomenda, portanto, uma base analítica para distinguir as fontes de ambiguidade. Ela nos leva também a perguntar pelas circunstâncias que fazem com que uma ambiguidade possa persistir ao longo do tempo"5 (p. 376). Dentre os tipos de ambiguidade, o autor cita a vaguidade e a incerteza, uma vez que têm sua contrapartida no erro a respeito das crenças espontâneas e equivocadas quanto ao modo como se devem enquadrar os acontecimentos.

Goffman $^{5}$ alerta para o fato de que as ambiguidades podem, quando não resolvidas ou resolvidas de forma inadequada, levar ao erro. Este, por sua vez, pode levar a uma formulação e a uma execução incipiente da ação. Essa questão passa a ser importante, uma vez que determinado quadro é interpretado de forma equivocada em razão da forma como foi enquadrado. De certo modo, a percepção incorreta de um fato pode envolver uma ação a partir de uma perspectiva radicalmente inaplicável e, com isso, estabelecer um conjunto de expectativas que não funcionarão. Parece ser esse o caso das notícias relativas ao crack no Jornal Nacional que serão discutidas e analisadas adiante neste trabalho. Analisemos o que Goffman explica: “[...] a questão não é apenas que um indivíduo pode incorrer em erro [...], mas que alguns desses erros vêm a ser uma questão de "enquadramento errôneo" e, consequentemente, o envolvem num erro sistematicamente mantido

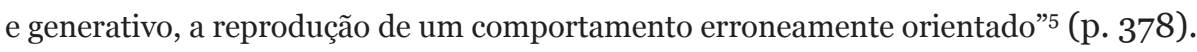

$\mathrm{Na}$ perspectiva de $\mathrm{McCombs}^{11}$, os enquadramentos servem como eficiente mecanismo de agrupamento de microatributos. Dessa maneira, os enquadramentos organizam e estruturam o pensamento para moldar a maneira como pensamos os temas de interesse público. Para além dos aspectos mencionados, McCombs ${ }^{11}$ salienta o que os enquadramentos podem gerar: "Os enquadramentos chamam nossa atenção para os pontos de vistas dominantes nas imagens, que não só sugerem o que é e o que não é relevante, mas também, de maneira ativa, promovem uma definição do problema determinado, uma interpretação causal, uma avaliação moral, e/ou uma recomendação de tratamento para o assunto descrito. ${ }^{11}$ (tradução própria, p. 174, 2006).

Esse cenário se altera quando um indivíduo se encontra em dúvida ou em erro sobre o que está ocorrendo, buscando estabelecer uma interpretação correta do quadro. Dizemos, então, que a relação do indivíduo com o quadro foi clarificada. Portanto, o que Goffman ${ }^{5}$ defende é que o quadro organiza mais do que o sentido, pois organiza também o envolvimento. $\mathrm{E}$ tal noção é fundamental para o tema de cobertura que selecionamos - o consumo do crack e as consequências sociais de tal consumo - pois como trata-se de uma pauta que envolve - ou deveria envolver - políticas de saúde pública, o enquadramento da imprensa tem potencial impacto sobre a interpretação correta do quadro em que se localiza o consumo do crack.

Também Tuchman ${ }^{13}$ oferece relevante contribuição no campo da comunicação no que diz respeito ao conceito de enquadramento. Segundo a socióloga, as notícias impõem um enquadramento que define e constrói a realidade. As notícias, segundo Tuchman, são "um recurso social cuja construção limita um entendimento analítico da vida contemporânea"13 (p. 215). Ela associa as categorias de notícia e o respectivo processo de produção com a maneira como a realidade é apresentada pelos noticiários, ou seja, pelo seu 
enquadramento. Neste sentido, a cobertura noticiosa sobre o consumo do crack tem influência sobre a compreensão analítica do fenômeno, o que, em um enquadramento mais plural e menos restrito traria maior capacidade analítica.

De acordo com Goffman, as perspectivas primárias naturais ou sociais acessíveis aos membros de um grupo social afetam um número maior de pessoas do que apenas os participantes de determinada atividade. Os que estão a observar ou são espectadores de determinado quadro social são profundamente afetados. "Parece que dificilmente podemos olhar alguma coisa sem aplicar um esquema primário, tecendo assim conjecturas sobre o que ocorreu antes e expectativas sobre o que provavelmente vai ocorrer agora" 5 (p. 65). A partir dessa contribuição do autor, refletimos sobre o que Tuchman ${ }^{13}$ infere das notícias e da realidade social e entendemos que, a partir do enquadramento que determinado fato noticioso recebe, há implicações para um número maior de pessoas que, com base em suas capacidades cognitivas, podem interpretar os fatos à luz dos enquadramentos fornecidos pelos meios de comunicação ou, ainda, gerar novos quadros interpretativos da experiência e da realidade social. "O jornalismo como prática institucionalizada, os constrangimentos organizacionais daí derivados, a visão dos jornalistas sobre o que é notícia - resultado da perspectiva que eles têm sobre a própria profissão - e a tendência que as notícias têm de privilegiar posições ideológicas hegemônicas, reforçando a manutenção do statu quo, dentre outros fatores, são fundamentais para uma compreensão dos modos como são promovidos os enquadramentos [...]"14 (p. 6).

Gitlin apud Porto ${ }^{9}$ apresenta a definição mais sistemática e clara do enquadramento. Segundo esse autor, os enquadramentos são recursos que organizam o discurso por meio de práticas específicas, como seleção, ênfase e exclusão, e, de alguma forma, constituem uma interpretação dos fatos narrados: "Os enquadramentos da mídia [...] organizam o mundo tanto para os jornalistas que escrevem relatos sobre ele, como também, em um grau importante, para nós que recorremos às suas notícias”9(p. 6).

A perspectiva apontada por Guazina e Martineli ${ }^{15}$ também se soma ao nosso estudo, por trazer relevantes contribuições acerca do conceito e das aplicações dos estudos de enquadramento e dos processos de seleção: "Assim, ao enquadrar, os narradores (jornalistas, apresentadores, comentaristas, etc.) definem pontos de vista e hierarquizam informações, selecionando algumas em detrimento de outras. Deste modo, o resultado de qualquer trabalho com características jornalísticas é eminentemente enquadrado, isto é, organizado a partir de princípios culturais compartilhados que estão na base da decisão de selecionar"15 (p. 110).

Portanto, desde a perspectiva apresentada, a maneira como a mídia seleciona e dispõe determinado assunto conduz à formação de enquadramentos que podem ser morais, dramáticos ou violentos. Um dos aspectos citados por Guazina e Martineli15 diz respeito à seleção, "[...] aspecto essencial do conceito de enquadramento". A ênfase em determinados aspectos e a omissão de outros pode ser determinante na construção de sentidos: "Quando uma informação é salientada em um texto (e aqui considera-se texto inclusive as imagens), ela se torna mais significativa e memorável para a audiência, indicando um modelo de interpretação dominante, isto é, uma orientação de interpretação a ser seguida"’15(p. 110).

De maneira próxima ao que as autoras assinalam, $\mathrm{Neveu}^{16}$ destaca que o estabelecimento da ordem do dia está associado à capacidade que os meios de comunicação têm de selecionar e produzir hierarquização da informação, exercendo uma influência que não diz respeito a moldar comportamentos, mas a definir os temas dignos de atenção por parte de uma coletividade a partir do enquadramento: "um conjunto, frequentemente limitado, de modos de tratamento de um assunto e seus diversos filtros que bloqueiam a cobertura dos acontecimentos que não entram nos quadros e não dispõem de mediadores sociais"16 (p. 144).

Segundo Sena, os enquadramentos apresentados - a autora se refere ao estudo realizado sobre notícias publicadas sobre o crack ao longo de dez anos -, porque falam sobre o mundo, são também produtores desse mundo: "As representações não são um dado de natureza, são construções sociais que revelam um jogo de forças, um cenário político"110(p. 23). 
O estudo de Sena ${ }^{10}$ a respeito de notícias publicadas sobre o crack, ao longo da primeira década deste século, em Belo Horizonte, capital de Minas Gerais, revelou os seguintes enquadramentos: impunidade, descontrole social, penetração em categorias blindadas/sagradas, guerra, terror, aumento do uso de drogas/violência, atentado a valores familiares/religiosos, degradação pessoal. A autora esclarece cada uma dessas categorias. Para sistematizar e organizar melhor as informações, o Quadro 1 apresenta a categoria de enquadramento usado por Sena ${ }^{10}$ e a respectiva caracterização ou definição da categoria.

Quadro 1 - Enquadramentos extraídos da pesquisa de Sena

\begin{tabular}{|l|l|}
\hline Enquadramento & Caracterização ou definição \\
\hline Impunidade & $\begin{array}{l}\text { Faz alusão a uma sensação compartilhada. Falta de penalização dos infratores } \\
\text { ligados ao crack. }\end{array}$ \\
\hline Descontrole social & $\begin{array}{l}\text { Destaca perda de controle do povo, incapacidade de manutenção da ordem } \\
\text { pública por parte da polícia. }\end{array}$ \\
\hline $\begin{array}{l}\text { Penetração em categorias } \\
\text { blindadas }\end{array}$ & $\begin{array}{l}\text { As notícias abordam profissionais de elite, como: de formação universitária, } \\
\text { profissionais ligados à segurança pública e mulheres destacadas pelo seu padrão } \\
\text { de beleza, como donas de casa, ou, simplesmente, pelo pertencimento ao gênero } \\
\text { feminino e o envolvimento com o crack. }\end{array}$ \\
\hline Terror & Foca crimes atribuídos ao crack. \\
\hline Aumento do uso de drogas & $\begin{array}{l}\text { As notícias evidenciam o aumento do número de usuários de crack ou o } \\
\text { acréscimo da violência ligadas ao comércio e ao uso de drogas. }\end{array}$ \\
\hline $\begin{array}{l}\text { Atentado aos valores } \\
\text { familiares/religiosos }\end{array}$ & $\begin{array}{l}\text { Caracteriza-se por matérias ofensivas a valores morais da instituição família e } \\
\text { afronta às crenças religiosas por parte de usuários e comerciantes do crack. }\end{array}$ \\
\hline Degradação pessoal & $\begin{array}{l}\text { Aborda o indivíduo destituído do grau da condição humana, as perdas que } \\
\text { vivencia ou a violência de seus atos. Referência à perda de algo que se } \\
\text { conquistou pelo crack. }\end{array}$ \\
\hline
\end{tabular}

Fonte: Sena $(2011)^{10}$.

Porto ${ }^{9}$ também oferece uma classificação dos enquadramentos. Segundo o autor, há os enquadramentos noticiosos e os interpretativos. Os enquadramentos noticiosos se referem aos padrões de apresentação, seleção e ênfase utilizados por jornalistas para organizar seus relatos e estão associados ao 'ângulo da notícia' no jargão jornalístico. Os enquadramentos noticiosos são resultado das escolhas feitas pelos jornalistas quanto ao formato, apresentação cujos resultados conferem ênfase seletiva a determinados aspectos de uma realidade percebida. Por outro lado, os enquadramentos interpretativos são os padrões de interpretação que promovem uma avaliação particular de temas, incluindo as definições de problemas, avaliações das causas e dificuldades, recomendações de tratamento, entre outros aspectos. Embora os jornalistas contribuam com seus respectivos enquadramentos interpretativos, esse tipo de enquadramento tem origem em atores sociais e políticos externos à prática jornalística - são as explicações que podem ser incorporadas ou não no discurso da mídia.

Ainda sobre enquadramentos, Porto ${ }^{9}$ explica que a natureza complexa e contraditória das mensagens da mídia não pode ser ignorada. Por essa razão, o autor apresenta a classificação sobre a 'forma' das mensagens televisivas. Segmentos restritos de enquadramento seriam aqueles que incluem somente um tipo de enquadramento interpretativo, enquanto segmentos plurais incluem mais de um enquadramento. Os segmentos plurais se dividem em: plurais-fechados, em que um dos enquadramentos é privilegiado ou enfatizado, e em plurais-abertos, em que nenhum enquadramento apresentado prevalece sobre o outro ou, 
nas palavras do autor, "é mais válido ou verdadeiro"9 (p.19). Os enquadramentos com forma 'episódica' não incluem enquadramentos interpretativos.

Segundo Porto9 , a classificação de segmentos demonstra que a mídia tende a apresentar certa diversidade de enquadramentos e, neste sentido, contribui para privilegiar determinadas interpretações hegemônicas da realidade, especialmente aquelas fornecidas pelas fontes oficiais.

\section{Corpus de análise}

Apresentamos a análise correspondente à cobertura jornalística do Jornal Nacional sobre o consumo do crack e as implicações sociais da droga no período de 2012 a 2017 e consideramos, para efeito de análise, as reportagens dos jornalistas que foram entrevistados para no sentido de ampliar nossa compreensão sobre as rotinas produtivas e o modus operandi da cobertura informativa acerca do tema. Ao todo, foram 31 reportagens, das quais 19 foram produzidas pelos 11 jornalistas entrevistados.

Para efeito de análise no que concerne à categoria enquadramento, entendido como princípio organizador que incorpora e enfatiza determinados atributos e, portanto, determina um ponto de vista dominante; e à categoria atributos, que pode ser compreendida como diferentes aspectos ou atributos que envolvem determinada questão ou problema, no caso desta pesquisa, o consumo do crack e as implicações sociais da droga, vamos considerar apenas as 19 reportagens cujos repórteres concederam entrevista em 2017: Ismar Madeira, César Menezes, Graziela Azevedo, Eduardo Tchao, César Galvão, Giuliano Tamura, Pedro Bassan, Renato Biazzi, Lília Teles, Giulliana Morrone, Fábio Turci.

\section{Enquadramentos e distorções}

Nossa análise se concentrou no Jornal Nacional por reconhecer o telejornal como o de maior audiência da televisão aberta brasileira à época do estudo e considerar que o alcance pode ter influência no modo como os assuntos são enquadrados e no modo como a opinião pública interpreta os assuntos. Bonner ${ }^{17}$ defende que o Jornal Nacional reflete "o que de mais importante aconteceu no Brasil e no mundo". Contudo, identificamos que essa máxima apresentada pelo editor-chefe do telejornal depende de uma variável importante e definidora: ser factual e se apresentar como um fenômeno novo. Assim, questionamos o critério de importância estabelecido pelo Jornal Nacional para cobrir jornalisticamente os assuntos e a relação de importância do consumo do crack e das implicações sociais da droga no contexto da sociedade brasileira, uma vez que esse consumo não é fenômeno novo no Brasil, embora seja importante e cause impactos na sociedade.

Percebemos que a cobertura jornalística do telejornal sobre o consumo do crack e as implicações sociais decorrentes da droga se concentrou nos anos de 2012 e 2013 em que as mídias repercutiam ações do governo federal em termos de políticas públicas de combate ao consumo da droga e em que prefeituras, como as de São Paulo e do Rio de Janeiro, iniciaram programas de combate ao consumo de crack. Contudo, identificamos lapsos temporais na cobertura - por conseguinte, ausência de cobertura sobre o assunto - que indicaram que o assunto concorreu com temáticas como Olimpíadas 2016, o impeachment da presidenta Dilma Rousseff e o surto do zika vírus. Em outras palavras, inferimos que o consumo da droga não se tornou agenda para o telejornal e não figurou entre os assuntos mais importantes para os telespectadores naquele ano, embora tenham persistido na realidade social dos grandes centros urbanos e dos municípios do interior do país.

\footnotetext{
i Dados de 2017 do Instituto Brasileiro de Opinião Pública e Estatística (Ibope) indicam que a Rede Globo é líder de audiência entre as emissoras de televisão aberta. O Jornal Nacional registrou 28,1 pontos de audiência em 2017 e, no período, figurou entre os três programas de maior audiência da emissora.
} 
As reportagens veiculadas no Jornal Nacional no período de 2012 a 2017 dão o enquadramento ao consumo do crack como problema epidêmico, sendo que esse quadro interpretativo apareceu, pelo menos, seis vezes em nossa análise. A palavra epidemia/epidêmica em referência à droga e à dependência química no tocante ao crack também esteve presente nas reportagens analisadas e na opinião dos jornalistas entrevistados em nossa pesquisa.

Não podemos perder de vista os estudos de Rui ${ }^{18}$ que apontam para um alarde da mídia quanto ao consumo do crack que culmina na aceleração de políticas públicas de enfrentamento e combate ao consumo do crack, não necessariamente, em diálogo com a complexidade do problema. Segundo a autora, há uma relação íntima entre a exposição midiática e o início das respectivas políticas públicas.

Identificamos, ainda, que a cobertura jornalística realizada pelo Jornal Nacional acerca do consumo do crack e das implicações sociais decorrentes do uso da droga privilegia a valorização do 'medo', do 'terror' e do 'pânico'. Essa percepção se dá no reconhecimento que temos de que o consumo do crack acontece nos pequenos e grandes centros urbanos e no fato de que a utilização ocorre em locais públicos, geralmente, de grande circulação de pessoas, a céu aberto, provocando certo 'incômodo' para a população. Nessa perspectiva, assinalamos que o 'medo' está relacionado aos valores-notícia apresentados que estão associados à violência e à criminalidade.

Via de regra, o assunto foi enquadrado, no material analisado, como uma questão de saúde pública, segurança pública e problema social crônico. Apesar de os enquadramentos noticiosos indicarem como o consumo do crack e as implicações sociais da droga foram etiquetados pelo Jornal Nacional, percebemos que, quando o telejornal tratou o assunto como de saúde pública, pouco avançou na proposta de discussões mais plurais, na prevenção do vício ou mesmo na formulação de proposições acerca de como solucionar o problema social apresentado, mostrando, quase sempre, a medicalização e a internação como alternativas para solucionar o problema. Contudo, Llistó ${ }^{19}$ orienta quanto à necessidade de buscar inserir a questão do consumo do crack a partir de uma perspectiva socioantropológica e menos baseada na medicalização.

Em nossa análise, identificamos que o telejornal adotou a compreensão de que, sendo um problema de saúde pública, o consumo do crack pode ser solucionado com a internação e a medicalização dos indivíduos viciados na droga. Observamos que essa compreensão parte do senso comum, apesar de o telejornal utilizar fontes oficiais e experts para falar do assunto. A hegemonia do discurso dominante das fontes oficiais e institucionais parece reduzir a importância de pesquisas realizadas que identificam que o consumo do crack tem relação com questões sociais complexas que antecedem o vício na droga. Esta abordagem - de que os problemas sociais precedem o consumo da droga e, ao contrário, não decorrem do vício - não foi feita pelo telejornal em nenhuma das reportagens analisadas. Neste aspecto, questionamos a abordagem do Jornal Nacional que focaliza o assunto reconhecidamente complexo ${ }^{20}$ sob um prisma ou mais de um prisma, privilegiando quase sempre um enquadramento noticioso em detrimento de outro, quando, em realidade, a questão do consumo do crack e as implicações sociais demandam, por parte da mídia, abordagem multidisciplinar e socioantropológica.

Identificamos que as reportagens que enquadraram o consumo do crack e as implicações sociais sob a perspectiva da segurança pública, associando o consumo da droga a contextos de violência, reforçam o que o senso comum já sabe sobre a droga, sobre os usuários de crack e sobre o contexto em que estão inseridos. Todavia, essas formulações já socialmente compartilhadas, normatizadas e institucionalizadas acerca do fenômeno do consumo do crack nem sempre correspondem integralmente à realidade. No caso dos Estados Unidos, Hart ${ }^{21}$ constatou que apenas um terço dos presos tinha cometido crimes sob influência de drogas. Embora pesquisas tenham sido realizadas em penitenciária no sul do Brasil e revelado que o consumo do álcool é o maior responsável por roubos e por gerar contextos de agressividade, as reportagens do Jornal Nacional, quando dão visibilidade e enquadram o assunto na perspectiva de segurança pública e violência, reforçam o quadro de referencialidades que associa o consumo do crack a cenários de violência. 
Reconhecemos que, nas reportagens que o Jornal Nacional veiculou sobre programas municipais que estabeleciam compensações - trabalho, moradia, dinheiro -, de alguma forma, o telejornal buscou demonstrar que o indivíduo viciado em crack é capaz de fazer escolhas racionais e de vencer o vício caso lhe sejam ofertadas oportunidades. Em entrevista realizada para a presente pesquisa de doutoramento, o neurocientista Carl Hart ${ }^{22}$ destacou que, após 30 anos, a mídia estadunidense avançou na forma como passou a abordar o assunto e que isso se deveu às ajudas fornecidas - oferta de moradia, emprego e dinheiro - aos usuários de crack. O Jornal Nacional chegou a veicular reportagens a partir dessa perspectiva, embora nas reportagens analisadas em que o telejornal focou a temática das compensações, não tenha trazido perspectivas científicas nas mensagens veiculadas, valendo-se apenas dos projetos e ações dos governos e prefeituras.

Identificamos, ainda, que o Jornal Nacional valeu-se de fontes oficiais e institucionais das áreas de saúde e segurança pública para interpretar o fenômeno e a realidade social acerca do consumo do crack que ora se apresentava, revelando, assim, a hegemonia do discurso do telejornal nos aspectos de saúde e segurança e estabelecendo correlação entre o consumo da droga e a necessidade de internação e medicalização e entre o consumo da droga e a criminalidade e a violência social. Por ser uma droga barata, Perrenoud e Ribeiro $^{23}$ esclarecem que o crack não é o foco dos traficantes responsáveis por mortes e pela manutenção do crime organizado. Contudo, o fato de ser uma droga consumida em espaços públicos de grande movimento e circulação de pessoas, em geral, por pessoas negras pertencentes a segmentos sociais mais baixos, desprovidas de condições de suprir necessidades básicas de consumo, o crack tende a ser retratado como droga letal, mais perigosa, degradante e desafiadora, assumindo, por vezes, um caráter demoníaco sobre o indivíduo que a consome. Consideramos a pesquisa de Acioli Neto e $\mathrm{Santos}^{24}$, que versa sobre o uso social e controlado do crack. Entretanto, em nossa análise das reportagens veiculadas no Jornal Nacional, não percebemos evidências que poderiam fornecer a interpretação para a sociedade de que o indivíduo pode fazer uso social e controlado da droga.

Consideramos que a cobertura jornalística do consumo do crack e das implicações sociais decorrentes da droga normatiza o consumo da droga como epidêmico. Retomamos o conceito da palavra epidemia de acordo com pesquisas na área de saúde pública. Conforme Barata ${ }^{25}$, a essência da epidemia está associada ao suporte dado por um conjunto de circunstâncias existentes em um lugar, em certo tempo e não à doença propriamente dita. A pesquisadora explica que a doença sempre se repete, enquanto a epidemia, nesse sentido, é única. Portanto, o que faz da epidemia um fato único é a especificidade do contexto no qual ocorre, e não a essência da doença em questão. Desse modo, nossa análise indica que a palavra epidemia se refere a um conjunto de fatores em determinado lugar e em determinado período. Chegamos, então, ao ponto de refletir que, no Jornal Nacional, algumas palavras são utilizadas, desconsiderando seu real significado. O consumo do crack, tal qual se apresenta na realidade social, não é episódico, transitório ou periódico no Brasil, como afirmam as reportagens analisadas. O consumo do crack é uma realidade social complexa que exige que diferentes esferas do poder atuem de forma dialogada e multidisciplinar, levando em conta os inventários e pesquisas já feitas sobre o tema no Brasil e no mundo, embora o contexto brasileiro apresente peculiaridades que não devem ser descartadas.

A partir da análise de uma parte do processo de enquadramento, que o Jornal Nacional ofereceu para os telespectadores, em suas mensagens jornalísticas, uma das interpretações possíveis acerca do consumo do crack e as implicações sociais da droga, embora esse recorte indique que o assunto, na amostragem analisada, tenha sido coberto, é que a cobertura pelo Jornal Nacional se deu de forma fragmentada. Isto pode estar relacionado às limitações impostas pelas rotinas produtivas que interferem na identidade profissional dos jornalistas, à experiência concreta de cada repórter com o assunto, entre outros fatores externos, como as abordagens propostas pela segurança pública e pela saúde pública quanto à definição do que é o indivíduo que consome crack, bem como das possibilidades de solução para o problema. Os 
resultados do nosso estudo demostram que há contradições entre as interpretações do assunto por parte de instituições diferentes ligadas ao Estado - nas diferentes esferas: municipal, estadual e federal -, a pesquisadores e instituições de pesquisa.

Por conseguinte, identificamos que a fragmentação no processo de enquadramento do consumo do crack e as implicações sociais decorrentes do uso da droga é processual também para essas instituições e, portanto, não depende tão somente dos fatores relacionados aos profissionais que produzem as reportagens. Os estigmas e as normatizações acerca da droga já são compartilhados socialmente entre os diferentes setores envolvidos na discussão do problema e parecem interferir na maneira como os repórteres entrevistados leem e representam a realidade social em suas reportagens.

Disso depreendemos que o consumo do crack e suas implicações sociais é um tema complexo porque é socialmente complexo e, por isso, é um tema que pode fornecer compreensões e ser ponto de partida para a análise do processo de enquadramento e de agendamento em outras pautas sociais complexas. Antes de ser um acontecimento jornalístico, antes mesmo de se tornar notícia e receber o tratamento jornalístico e os respectivos enquadramentos, o tema se apresenta como socialmente complexo, o que pode estar relacionado ao fato de que o processo de agendamento e de enquadramento sobre o assunto acontece antes de passar pela mídia e, portanto, antes da cobertura jornalística, embora a cobertura feita pelo Jornal Nacional, no período analisado, pareça incidir sobre o fenômeno e a compreensão que os telespectadores possam ter do assunto.

Uma vez que a mídia - especificamente o Jornal Nacional - tem papel preponderante na construção dos mapas cognitivos da sociedade, conforme observamos nas teorias da opinião pública, observamos que, no período de nossa análise, quando o Jornal Nacional agendou e enquadrou o assunto, o telejornal privilegiou os aspectos relativos ao factual. Quando o telejornal agendou e enquadrou o consumo do crack e suas implicações sociais a partir das temáticas da saúde pública, focalizou a internação e a medicalização dos usuários de crack. Quando o Jornal Nacional abordou o assunto como problema de segurança pública, focalizou a repressão e o encarceramento como possíveis soluções. Desse modo, inferimos que o telejornal tende a pautar também as ações do Estado em termos de políticas públicas e, nesse sentido, ao fornecer um quadro distorcido da realidade social, em certa medida, tende a distorcer também o modo como essas políticas públicas podem ser formuladas.

Em nossa observação, constatamos que o Jornal Nacional enquadrou o consumo do crack e suas implicações sociais no período analisado nesta pesquisa, refletindo os processos pelos quais o acontecimento passa para se tornar noticiável, envolvendo as condições de produção do material jornalístico, as experiências e vivências dos jornalistas, os princípios editoriais da empresa jornalística e as visões de mundo e os posicionamentos das fontes jornalísticas utilizadas no discurso do telejornal. Embora o consumo do crack seja um problema social complexo, o telejornalismo produzido pelo Jornal Nacional cobriu jornalisticamente o assunto com uma abordagem factual que também é comum nesse telejornal para temas que não têm a mesma complexidade.

\section{À guisa de conclusão}

Diante do exposto, reconhecemos a complexidade do tema a ser retratado pelo Jornal Nacional e consideramos que o consumo do crack e as implicações sociais da droga é um fenômeno inserido em um processo social mais amplo, que demanda a multiplicidade de olhares e de perspectivas de compreensão do fenômeno. Assim, embora nossas evidências nos indiquem que o Jornal Nacional, em razão do formato, da escassez de tempo e de sua abrangência, não tenha condições de ofertar conteúdos mais contextualizadores e profundos, somos provocados a pensar conforme Weaver ${ }^{26}$ : se, por um lado, a noção de que o acontecimento e sua característica de factualidade seja o ponto de partida do noticiário televisivo conforme 
identificamos nas teorias do jornalismo e nas entrevistas realizadas com os jornalistas responsáveis pela cobertura do consumo do crack no Jornal Nacional, por outro, parece plausível que não sejam a razão de ser do telejornalismo, dada a abrangência e a importância que o telejornal de maior audiência da televisão brasileira assume como produto capaz de oferecer "o que de mais importante aconteceu no Brasil e no mundo", conforme Bonner ${ }^{17}$.

Não obstante, reconhecemos que as rotinas produtivas do telejornal - que envolvem o fazer televisivo e o fazer jornalístico - determinam sobremaneira o modo como o Jornal Nacional realizou a cobertura sobre o consumo do crack no período analisado: a espetacularização, o sensacionalismo, a presença de generalizações e simplificações e a disseminação de estereótipos e estigmas consolidados e compartilhados socialmente preponderam, em detrimento da profundidade e da conxtextualização. Uma vez que - ao sofrerem cotidianamente as pressões do tempo e do espaço, considerados elementos da distorção involuntária pela teoria do newsmaking - os jornalistas tendem a simplificar o trabalho de apuração e edição na cobertura do Jornal Nacional, comprometendo, em certa medida, a maneira como os telespectadores vão compreender o fenômeno do consumo do crack e suas respectivas implicações sociais.

Uma vez que a mídia - especificamente o Jornal Nacional - tem papel preponderante na construção dos mapas cognitivos da sociedade, conforme observamos nas teorias da opinião pública, observamos que, no período de nossa análise, quando o Jornal Nacional enquadrou o assunto, o telejornal privilegiou os aspectos relativos ao factual. Quando o telejornal enquadrou o consumo do crack e suas implicações sociais a partir das temáticas da saúde pública, focalizou a internação e a medicalização dos usuários de crack. Quando o Jornal Nacional abordou o assunto como problema de segurança pública, focalizou a repressão e o encarceramento como possíveis soluções. Assim, inferimos que o telejornal tende a pautar também as ações do Estado em termos de políticas públicas e, neste sentido, ao fornecer um quadro distorcido da realidade social, em certa medida, tende a distorcer também o modo como essas políticas públicas podem ser formuladas.

\section{Referências}

1. Confederação Nacional de Municípios (BR). Observatório do crack [Internet]. Brasília: CNM, 2011 [citado 23 ago. 2019]. Disponível em: http://www.cnm.org.br/cms/biblioteca/ ObservatoriodoCrack(2011).pdf

2. Bastos FIPM, Vasconcelos MTL, Boni RB, Reis NB, Coutinho CFS. Levantamento Nacional sobre o uso de drogas pela população brasileira. Rio de Janeiro: Fiocruz/Icict; 2017.

3. Bastos FIPM, Bertoni N. Pesquisa Nacional sobre o uso de crack: quem são os usuários de crack e/ou similares do Brasil? Quantos são nas capitais brasileiras?. Rio de Janeiro: Fiocruz; 2014.

4. Lippmann W. Opinião pública. Petrópolis: Vozes; 2010.

5. Goffman E. Os quadros da experiência social: uma perspectiva de análise. Petrópolis: Vozes; 2012.

6. Ferreira FV. O papel do factual nos processos de agendamento e de enquadramento no telejornalismo. [Tese]. Brasília, DF: Faculdade de Comunicação; 2018.

7. Bardin L. Análise de conteúdo. São Paulo: Editora 70; 2011.

8. Goffman E. Frame analysis. Boston: Northeastern University Press; 1986.

9. Porto MP. Enquadramentos da mídia e política. In: $26^{\circ}$ Encontro Anual da Associação Nacional de PósGraduação e Pesquisa em Ciências Sociais - Anpocs; Caxambu-MG, Brasil; 2002 out. S.I.: s.n.; 2002.

10. Sena LL. O crack como fenômeno midiático: demônios e silêncios. In: Congresso de Opinião Pública da Wapor; Belo Horizonte-MG, Brasil; 2011 maio; S.I.: s.n.; 2011.

11. Mccombs M. Estableciendo la agenda. El impacto de los medios en la opinión pública y en el conocimiento. Barcelona: Paidós; 2006. 
12. Correia JC. O lugar do framing nas sociedades complexas. [Internet]. 2012 [citado 17 jul. 2019]. Disponível em: https://www.academia.edu/27958792/O lugar do framing nas sociedades complexas?auto $=$ download.

13. Tuchman G. Making news: a study in the construction of reality. New York: The Free Press; 1978.

14. Carvalho CA. Sobre limites e possibilidades do conceito de enquadramento jornalístico. Rev Contemp [Internet]. $2009 \mathrm{dez}$ [citado 23 jul. 2019];7(2):1-15. Disponível em: http://www.portalseer.ufba.br/ index.php/contemporaneaposcom/article/view Article/3701

15. Guazina L, Martineli F. Catwalk eletrônico: enquadramentos da moda no GNT Fashion1. Rev Animus [Internet]. 2012 [citado 23 jul. 2019];11(25):106-30. Disponível em: http://cascavel.ufsm.br/revistas/ ojs-2.2.2/index.php/animus/article/view/6893.

16. Neveu E. Sociologia do jornalismo. São Paulo: Loyola; 2006.

17. Bonner W. Jornal Nacional: modo de fazer. São Paulo: Globo; 2009.

18. Rui T. Nas tramas do crack: etnografia da abjeção. São Paulo: Terceiro Nome; 2014.

19. Llisto MJC. Estrategias de prevención respecto al consumo de sustancias adictivas a partir del estudio de los perfiles de los consumidores. In: Cambra UC, Iturrizaga AU, Hevia TM. Comunicación y Salud. Nuevos escenarios y tendencias. Madri: Editorial Complutense; 2011. p. 125-141.

20. Bruck MS. Crack na imprensa: imaginários e modos de representação do jornalismo sobre o surgimento e a explosão da droga em Belo Horizonte (MG, Brasil). Brazilian Journalism Research [Internet]. 2013 [citado 15 jul. 2019]; 9(20):174-93. Disponível em: http://bjr.sbpjor.org.br/bjr/article/viewFile/513/446.

21. Hart C. Um preço muito alto: a jornada de um neurocientista que desafia nossa visão sobre as drogas. Rio de Janeiro: Zahar; 2014.

22. Hart, C. Entrevista concedida a Fernanda Vasques Ferreira. Aplicativo Skype, 29 nov. 2017.

23. Perrenoud LO, Ribeiro M. Histórico do consumo de crack no Brasil e no mundo. In: Laranjeira R, Ribeiro M. O tratamento do usuário de crack. Porto Alegre: Artmed; 2012. p. 33-38.

24. Acioli Neto, ML; Santos, MFS. Os usos sociais do crack: construindo uma clínica situada culturalmente. Recife: Editora UFPE, 2015.

25. Barata RCB. Epidemias. Cad. Saúde Pública [Internet]. 1987 jan-mar [citado 20 jul. 2019];3(07). Disponível em:http://www.scielo.br/scielo.php?script=sci abstract\&pid= S0102-311X1987000100002\&ln $\mathrm{g}=\mathrm{en} \& \mathrm{nrm}=\mathrm{iso} \& \mathrm{t} \operatorname{lng}=\mathrm{pt}$

26. Weaver PH. As notícias de jornal e as notícias de televisão. In: Traquina N. Jornalismo: questões, teorias e "estórias". Florianópolis: Insular; 2016. p. 397-412. 